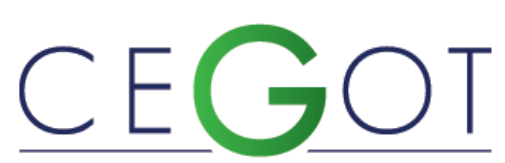

Centro de Estudos de Geografia e Ordenamento do Território

Geografia e Ordenamento do Território, Revista Eletrónica Centro de Estudos de Geografia e Ordenamento do Território http://cegot.org

TAVARES, JESSICA

Universidade Federal do Espírito Santos (UFES) /Centro de Ciências Humanas e Naturais (CCHN) /Departamento de geografia

Av. Fernando Ferrari, 514, Goiabeiras | Vitória - ES/ Brasil. CEP 29075-910 jessicamonteirost@gmail.com

LOVATE, THAís

Universidade Federal do Espírito Santos (UFES) /Centro de Ciências Humanas e Naturais (CCHN) /Departamento de geografia

Av. Fernando Ferrari, 514, Goiabeiras | Vitória - ES/ Brasil. CEP 29075-910 thais.lovate@gmail.com

ANDRADE, ÍTALA

Universidade Federal do Espírito Santos (UFES) /Centro de

Ciências Humanas e Naturais (CCHN) /Departamento de

geografia

Av. Fernando Ferrari, 514, Goiabeiras | Vitória - ES/ Brasil. CEP 29075-910

italalandrade@outlook.com

\title{
Transição epidemiológica e causas externas de mortalidade na região sudeste do Brasil
}

Epidemiological transition and external causes of mortality at southeast region of Brazil

Referência: Tavares, Jessica; Lovate, Thaís; Andrade, Ítala (2018). Transição epidemiológica e causas externas de mortalidade na região sudeste do Brasil. Revista de Geografia e Ordenamento do Território (GOT), n. ${ }^{\circ} 15$ (dezembro). Centro de Estudos de Geografia e Ordenamento do Território, p. 453-479, dx.doi.org/10.17127/got/2018.15.019

\section{RESUMO}

As reflexões presentes neste trabalho se enquadram no campo da geografia da população, e utilizam a teoria da transição epidemiológica como base. Foram utilizados dados relativos aos grupos de causas de mortalidade no Brasil (CID-10) disponibilizados pelo Departamento de Informática do SUS bem como dados do grupo de causas externas: acidentes de transporte e agressões, especificamente, dos Estados da região Sudeste do Brasil. Com esses dados calcularam-se os indicadores de razão de sexo, mortalidade proporcional por grupos de causas, proporção por idade e proporção por sexo. Observou-se, com os resultados dos indicadores para o ano de 2015, o predomínio das doenças degenerativas do organismo como maior causa de mortalidade em detrimento dos óbitos por doenças infecciosas e parasitárias. Os homens jovens apresentaram sobremortalidade por acidentes de transportes e agressões.

Palavras-chave: transição epidemiológica, mortalidade, causas externas, acidentes de transportes, agressões, região sudeste.

\section{ABSTRACT}

The study present in this paper within the field of population geography, and use the theory of epidemiological transition as a basis. Data from groups of causes of mortality in Brazil 
(CID-10) made available by the Ministry of Health were analyzed as well as data from the external causes group, of the categories: road traffic accident and aggressions, specifically, states of Southeast region in Brazil. Indicators of proportional mortality by groups of causes, sex ratio, age proportion and sex proportion were calculated with this data. As a result of indicators for the year 2015 it was noted the majority of mortality for degenerative diseases to the detriment of deaths due to infectious and parasitic diseases was observed. Young men presented an excess mortality in relation to deaths by transports accidents and aggressions.

Keywords: epidemiologic transition, mortality, external causes, road traffic accident, aggressions, southeast region.

\section{Introdução}

A mortalidade é um dos componentes da dinâmica demográfica (juntamente com a natalidade e o saldo migratório). É um fenômeno individual e ao mesmo tempo coletivo, reflexo não só dos fatores biológicos e genéticos como também e, principalmente, do contexto socioeconômico e cultural da população.

De acordo com Yunes (1991, p.321), "os níveis de saúde afetam todos os componentes da dinâmica populacional", ou seja, exercem influência sobre a mortalidade, fecundidade e fluxos migratórios. E complementa: "A análise e interpretação dos dados relativos às doenças de massa e à sua erradicação sempre se baseiam em dados populacionais." (YUNES, 1991, p.323). Por isso mesmo, esses estudos estão diretamente associados à área da geografia chamada de geografia da população, que estuda os componentes da dinâmica populacional. Derruau (1973, p. 13) afirma que geografia da população é, "no entanto, uma geografia, o que quer dizer que, depois de estudar os números, relaciona-os com outros elementos do complexo geográfico". O autor afirma ainda que "o estudo dos fenómenos respeitantes à população integram-se num feixe de explicações: explicam a geografia e por ela são explicados." (DERRUAU, 1973, p. 18).

No campo dos estudos populacionais há diversos esforços na formulação de teorias, no entanto, deve-se considerar as estreitas relações entre estes fundamentos dadas a natureza do objeto do qual emergem, a população. Sendo assim, entendemos que a teoria da transição epidemiológica desenvolve-se paralelamente à transição demográfica, tecnológica e social que vigora em diferentes partes do mundo. 
As mudanças nos padrões de morbidade e mortalidade da população são a principal preocupação da transição epidemiológica. Nessa teoria observa-se a passagem de um estágio onde predominavam as mortes causadas por doenças infecciosas e parasitárias para um outro, onde prevalecem os óbitos por doenças degenerativas, crônico-degenerativas e as causas externas (PRATA, 1992). A primeira fase da transição demográfica corresponde à queda da taxa de mortalidade que se dá, em grande parte, por fatores relacionados com a transição epidemiológica. Observa-se portanto, uma relação entre as transições demográfica e epidemiológica, uma vez que, a teoria da transição epidemiológica baseia-se nas mudanças dos padrões de saúde e suas reverberações demográficas, econômicas e sociais.

Sabe-se que, nos últimos anos, os indicadores demográficos da população brasileira têm passado por intensas modificações (PEREIRA et al., 2015). É o caso do aumento da expectativa de vida, redução da taxa de fecundidade, redução da mortalidade infantil e da mortalidade geral por doenças infecto-contagiosas, por exemplo. Esses fatos nos remetem às mudanças no padrão de vida da população.

Assim sendo, este trabalho visa apresentar e analisar o número de casos de mortalidade de acordo com as categorias da Classificação Internacional de Doenças e Problemas Relacionados à Saúde (CID-10) no ano de 2015, da população dos estados de São Paulo, Rio de Janeiro, Minas Gerais e Espírito Santo, que integram a região sudeste do Brasil (Mapa 1), a mais populosa e com maior taxa de urbanização do país (IBGE, 2010), a partir de dados disponibilizados pelo Departamento de Informática do Sistema Único de Saúde (DATASUS). 


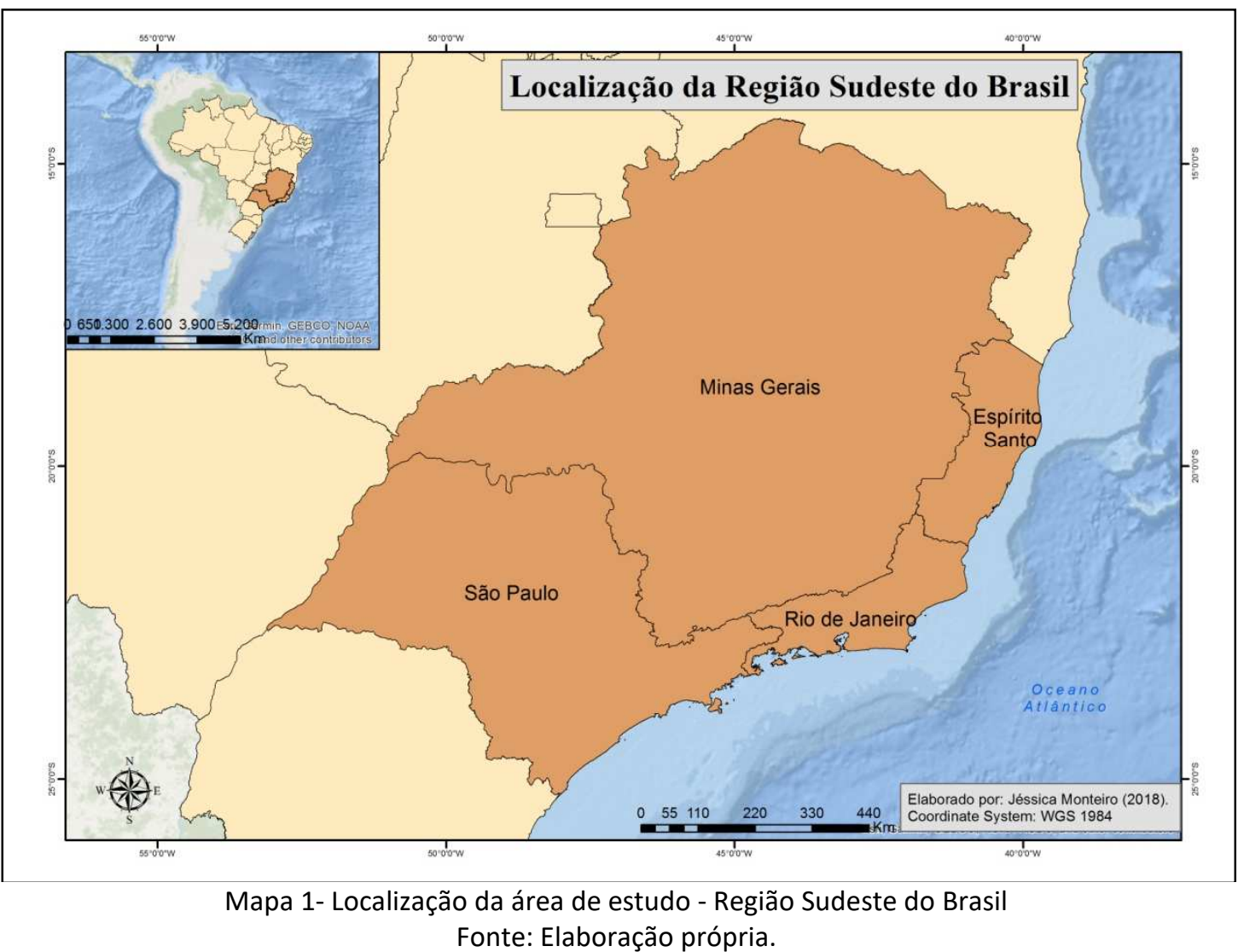

O objetivo do trabalho é observar e problematizar o panorama recente da mortalidade em tais estados, tendo em vista a atual fase de transição epidemiológica pela qual atravessa o Brasil. À luz desse processo foi feita uma análise entre o número de casos dos respectivos estados através dos valores absolutos, relativos e também do cálculo dos seguintes indicadores: mortalidade proporcional, distribuição etária e razão de sexo entre os grupos de causas. Entre as 22 categorias de causas de mortalidade, foi escolhida a denominada "Causas externas" para uma análise específica. Nesta categoria de causas, foram analisadas as duas com maior incidência de óbitos: acidentes de transporte e agressões. Tal escolha foi feita pois essas causas destoam do previsto na teoria da transição epidemiológica e apresentaram participação significativa no número de óbitos.

Estudos desse tipo são relevantes, pois as mudanças no perfil epidemiológico de uma população podem influenciar diretamente suas vidas, tanto individual quanto coletivamente, além de serem importantes para direcionar os recursos públicos e a gestão, por meio de planejamento de ações na área de saúde e qualidade de vida, por exemplo, contribuindo na elaboração de políticas públicas eficientes. 


\section{Aspectos conceituais}

Uma análise populacional envolve grande diversidade de fatores que influenciam na forma como cada sociedade vivencia o seu processo de evolução demográfica. Assim, com a finalidade de formular bases para o estudo populacional algumas teorias vêm sendo desenvolvidas levando em conta as características sociais, econômicas e culturais que determinam a formação dos grupos populacionais.

A teoria da transição epidemiológica encontra-se inserida em tal conjunto de fundamentos, a qual emerge paralelamente à teoria da transição demográfica, tecnológica e social. Conceitualmente, a teoria da transição epidemiológica destaca a complexa mudança nos padrões de saúde e de doenças e sobre a interação entre estes padrões e as suas consequências demográficas, econômicas e sociológicas.

A teoria da transição epidemiológica, nesse sentido, volta-se para o entendimento da modificação dos padrões de saúde e doenças que atingem a população. Tal teoria observa a mudança de um padrão onde as doenças infecciosas e parasitárias ocasionavam altas taxas de mortalidade para um padrão em que as doenças degenerativas do organismo tornam-se a maior causa de mortalidade na população. Dessa forma, entende-se por transição epidemiológica as transformações "nos padrões de morte, morbidade e invalidez que caracterizam uma população específica e que, em geral, ocorrem em conjunto com outras transformações demográficas, sociais e econômicas" (SCHRAMM et al., 2004, p. 898).

Vermelho e Monteiro (2002) afirmam que a transição epidemiológica consiste nas mudanças nos padrões de morbilidade e mortalidade de uma comunidade. De acordo com estes autores, essa teoria tem como premissa principal o fato de que a mortalidade e a natalidade são as forças mais importantes da dinâmica demográfica. Isso porque a primeira estabelece a tendência e o ritmo das mudanças que ocorrem na maioria das sociedades e a segunda assume a direção quando a mortalidade já atingiu níveis baixos.

O aumento da expectativa de vida da população levou a uma mudança dos grupos de causas de doenças. A população que sobrevive aos primeiros anos de idade, os de maior fragilidade, têm a possibilidade de atingir idades avançadas, o que acarreta o envelhecimento da população e a mudança do grupo de causas de doenças responsáveis pela mortalidade. Nesse sentido, com o aumento do grupo de pessoas em idade avançada, 
as neoplasias e as doenças do sistema circulatório e respiratório passaram a ser o grupo de causas de doenças de maior peso na composição dos índices de mortalidade.

Omran (1971) mencionou que as modificações nos padrões de mortalidade ocorrem com diferentes intensidades nos países e que a análise de dados individuais de países distintos é importante para revelar as disparidades nos padrões de transição epidemiológica. De acordo com o autor, diferenças peculiares no padrão, no ritmo, nos determinantes e nas consequências da mudança populacional diferenciam três modelos básicos da transição epidemiológica: o modelo clássico ou ocidental, o modelo acelerado ou semi-ocidental e o modelo contemporâneo ou atrasado com as suas variações. Os dois primeiros modelos referem-se a países que tiveram o seu declínio na mortalidade antes do século $\mathrm{XX}$, com a natalidade atingindo níveis baixos no modelo clássico e moderados no semi-ocidental. No modelo retardado o declínio considerável na mortalidade só veio a ocorrer no início do século XX e o da natalidade, mais ou menos, na metade do século (VERMELHO; MONTEIRO, 1992).

Segundo Omran (1971), o "terceiro mundo" está sendo significativamente influenciado pela tecnologia médica. O Brasil foi um desses países fortemente influenciados pelo controle de doenças por meio dos programas de saúde pública e da revolução sanitária. Segundo a pesquisa realizada por Omran (1971), ainda em 1930 as doenças infecciosas e parasitárias eram as que mais ocasionaram mortes no país, enquanto na mesma época países desenvolvidos como Inglaterra, País de Gales e Japão encontravam-se em fases avançadas do processo de transição, e até mesmo o Chile já havia iniciado o processo de regressão nesse grupo de causas de mortes. A implementação de campanhas de imunização de saúde pública, as obras para o provimento de saneamento básico e as mudanças sociológicas em relação à higienização e à nutrição formaram as bases do início da transição epidemiológica no Brasil. Entretanto, o processo de transição ocorre de maneira diferenciada também entre as regiões do país, como afirmam Prata (1992), Schramm et al. (2004), Vermelho e Monteiro (2002) e Castiglioni (2012). Observa-se que as regiões Sudeste e Sul são as mais desenvolvidas no processo de transição epidemiológica e demográfica em relação às outras três regiões brasileiras. Isso pode ocorrer devido à grande dimensão territorial do país que atua como empecilho ao desenvolvimento econômico, ao acesso à informação e à inserção de políticas públicas. 
Schramm et al. (2004), por sua vez, expõem que o conceito de transição epidemiológica tem merecido críticas, uma vez que, a transformação dos padrões de saúde não obedece aos mesmos parâmetros de sequência, intensidade e velocidade, em diferentes regiões. Segundo esses autores, no Brasil a diferenciação regional coloca barreiras ao avanço do processo de transição epidemiológica fazendo com que as regiões Sul e Sudeste encontramse em patamares avançados, a região centro-oeste em situação intermediária e as regiões Norte e Nordeste atrasadas em relação às outras. Destacam que há uma sobreposição entre as etapas nas quais predominam as doenças transmissíveis e crônico-degenerativas, assim como a reintrodução de doenças como dengue e cólera ou o recrudescimento de outras como malária, hanseníase e leishmaniose (SCHRAMM et al., 2004).

Além dessa sobreposição nas etapas do processo de transição epidemiológica, é necessário observar o incremento das causas externas de morte que destoam das causas de morte esperadas em estágios avançados da transição epidemiológica. Laurenti (1975) já atentava para o fato de que o processo de urbanização acelerada pelo qual passava os países da América Latina trouxe sérias consequências e criou "problemas para a saúde coletiva e para os serviços de assistência médica" (p. 240). No período analisado pelo autor, ele atribui a superioridade do número de óbitos por acidente de trânsito da América Latina em relação aos Estados Unidos da América à falta de instrução de motoristas e pedestres, bem como a precarização das vias de transporte.

Arranz e Gil (2009) ao analisarem o número de casos de acidentes de transporte na Espanha entre os anos de 1996 e 2002, observaram que apesar do aumento da segurança dos veículos, o excesso de velocidade e o abuso de álcool influenciam consideravelmente no número de óbitos em trânsito, principalmente na faixa etária dos 15 aos 29 anos. De acordo com a Spanish National Anti-Drug Campaign (2001), os motoristas alcoolizados são responsáveis por uma em cada quatro mortes entre os jovens do sexo masculino na faixa etária citada anteriormente na Espanha.

Castiglioni (2012) comenta sobre a sobremortalidade masculina na maioria dos grupos de causas. De acordo com a autora, "as causas externas aparecem como um grupo particular, no qual as chamadas 'mortes violentas' destoam do quadro explicativo que engloba os processos transicionais descritos" (CASTIGLIONI, 2012, p. 2). Segundo ela, essas mortes violentas "apresentam forte grau de diferenciação com relação ao sexo decorrente 
principalmente de fatores comportamentais e culturais" (CASTIGLIONI, 2012, p.15). Perspectiva semelhante pode ser observada em Vermelho e Jorge (1996), quando afirmam que

[...] o Brasil, e em especial para os grupos de jovens, as mudanças demográficas associadas aos processos de industrialização e urbanização, o desenvolvimento tecnológico, as mudanças na estrutura produtiva ... a ampliação do mercado de drogas, [...] configuram o novo padrão epidemiológico (VERMELHO; JORGE, 1996, p.321).

Por conseguinte, é importante notar a influência que as revoluções tecnológicas e informacionais trouxeram para mudança de estilo de vida. Além de uma reestruturação no sistema dos níveis básico e hospitalar para o diagnóstico e tratamento das enfermidades, é necessário que a população seja orientada preventivamente. Porém, cabe ressaltar que não só a transição epidemiológica pode aparecer como problema para a saúde pública, como também as causas externas de morte que passaram a ocupar significativa porção do número de óbitos como também dos gastos hospitalares.

Pereira et al. (2015) fizeram uma descrição do processo de transição epidemiológica no Brasil, mostrando as transformações que ocorrem no modelo epidemiológico do país, com o avanço das causas externas de mortalidade. Essas mudanças são, segundo os autores, decorrentes:

não apenas da reemergência ou presença constante dos casos de doenças infecciosas e parasitárias - se não com casos elevados de mortalidade, mas ainda com casos relevantes de morbidade, detectada pelo sistema de vigilância epidemiológica e pelos registros ambulatoriais e hospitalares - como também pelo importante crescimento das causas externas, expressão da violência social em suas diferentes formas (PEREIRA et al., 2015, p. 101-102).

\section{Aspectos metodológicos}

Para atender aos objetivos do trabalho foi realizada uma análise descritiva por meio de alguns indicadores de distribuição por idade e sexo e algumas proporções, utilizando dados disponibilizados pelo Ministério da Saúde por meio do DATASUS para o ano de 2015 no Brasil e nos Estados da região sudeste (Espírito Santo, Minas Gerais, Rio de Janeiro e São Paulo).

Os dados foram extraídos e organizados em tabelas, de acordo com os grupos etários e o sexo. Em seguida, os cálculos foram feitos de acordo com o método de cada indicador. Os resultados serão apresentados por meio de tabelas e gráficos. Cabe ressaltar que nas 
tabelas e gráficos não constam a causa de morte $\mathrm{n}$ ․ XIX, por lesões, envenenamento e algumas outras consequências de causas externas, pois estas não apresentaram nenhum registo. Uma possibilidade é a de que o grupo de causas constante neste capítulo tenha sido incluído em outro, como o capítulo XX por exemplo (causas externas de morbilidade e mortalidade).

Além disso, vale ressaltar que as causas de mortalidade foram pesquisadas de acordo com o registo por local de residência do falecido pois este é o mais indicado para o cálculo de indicadores, uma vez que o registo por local de ocorrência do óbito apresenta lacunas com relação à deslocação constante realizada pela população.

Os indicadores são importantes aliados na análise e interpretação de dados sobre população. Por meio deles é possível analisar o envelhecimento populacional, assim como avaliar os avanços ou recuos nas condições de vida da população, apontar a eficácia ou ineficácia das políticas públicas, permitindo assim definir prioridades das políticas sociais e alocação do dinheiro público, entre outros usos.

Os indicadores sociais podem ser classificados de acordo com a área temática da realidade social a qual se referem. Portanto, existem os indicadores educacionais, indicadores de saúde, de mercado de trabalho, habitacionais, demográficos, de segurança pública, de renda e desigualdade, entre outros (JANNUZZI, 2003). Neste estudo foram utilizados alguns indicadores demográficos resultantes da distribuição por sexo, estrutura etária e volume da população como razão de sexo, proporção de sexo e outros indicadores relacionados com a mortalidade de uma determinada população num determinado recorte temporal, de acordo com as causas de mortalidade.

O indicador de mortalidade proporcional por grupos de causas (proporção) mede a participação relativa dos principais grupos de causas de morte no total de óbitos. Para calcular a proporção por grupo de causa de mortalidade o cálculo é o seguinte:

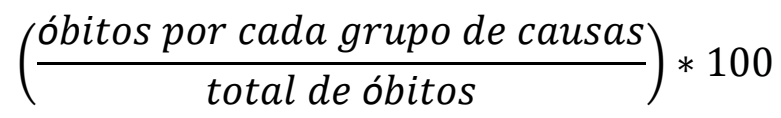

O indicador proporção por idade mostra a proporção de cada faixa etária no grupo total de óbitos para aquele tipo específico de causa, ou seja, quanto cada faixa etária representa no total de óbitos. O cálculo é o seguinte: 


$$
\left(\frac{\text { óbitos por cada faixa etária }}{\text { total de óbitos }}\right) * 100
$$

Já a razão de sexo (RS) é calculada pela "razão entre o número de homens e o número de mulheres em uma população" (IBGE, 2016a, p. 128). O método de cálculo é o seguinte:

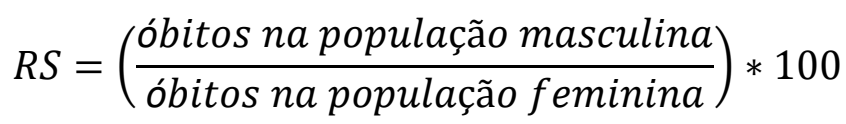

Essa expressão representa a relação quantitativa entre os sexos. Se o resultado obtido for igual a 100, o número de homens e de mulheres é equivalente; acima de 100, há predomínio de mortalidade entre homens; abaixo de 100, predomínio de mulheres.

A razão de sexo pode ser calculada para as causas totais e também por cada grupo de causas, para se obter uma visão mais detalhada da população em estudo.

O indicador de proporção de sexo reflete o percentual de homens ou mulheres no total de óbitos em determinado período. É calculado da seguinte maneira para determinar a proporção geral de homens:

$$
\left(\frac{\text { total de óbitos na população masculina }}{\text { total geral de óbitos }}\right) * 100
$$

Para encontrar a proporção de mulheres:

$$
\left(\frac{\text { total de óbitos na população feminina }}{\text { total geral de óbitos }}\right) * 100
$$

Os óbitos serão analisados por residência, ou seja, serão levados em consideração, o número de óbitos ocorridos, contados segundo o local de residência do falecido, nos anos considerados.

\section{Resultados e discussões}

Beaujeu-Garnier (1980, p. 3), afirma que "é função do geógrafo descrever os fatos no contexto de seu ambiente atual, estudando também suas causas, suas características 
originais e suas possíveis consequências". Nesse sentido, serão analisado alguns aspectos relacionados às condições de saúde e mortalidade da população brasileira.

\begin{abstract}
A saúde, além de constituir um direito de todos, deve ser encarada tanto como um meio quanto como um objeto do desenvolvimento econômico e social. As condições de saúde pública de um país, ou de uma região estão intimamente ligadas à dinâmica populacional de um lado, e aos demais processos econômicos e social, de outro. Estas três ordens de variáveis devem, sempre que possível, ser analisadas em conjunto, dadas as relações de mútua dependência que existem entre elas (YUNES, 1991, p.321).
\end{abstract}

\title{
4.1. Grupos de causas de mortalidade por residência no Brasil em 2015
}

Entre os grupos de causa de mortalidade no Brasil no ano de 2015, o que mais gerou óbitos foi o das doenças no aparelho circulatório $(27,67 \%)$ e entre elas estão o enfarte agudo do miocárdio e outras doenças cardíacas e hipertensivas (Gráfico 1). O segundo grupo de doenças que mais gerou óbitos foram as neoplasias (tumores), correspondendo a $16,60 \%$ do total. De acordo com o Instituto Nacional de Câncer (INCA, 2003, p. 1), esse valor é "resultado de uma tendência que também ocorre em outros países desenvolvidos ou em desenvolvimento. Por ser uma doença característica de populações mais idosas, o câncer passa a vitimar mais pessoas à medida em que aumenta a longevidade". Esse aumento também pode ter relação com a qualidade da alimentação da população que cada vez mais consome alimentos industrializados e com alto teor de agrotóxicos, o que é extremamente preocupante.

\footnotetext{
XX. Causas externas de...

XVII.Malf cong deformid e... 0,86

$\begin{array}{ll}\text { XV. Gravidez parto e puerpério } & 0,15\end{array}$

XIII. Sist osteomuscular e tec... $\quad 0,43$

$\mathrm{XI}$. Aparelho digestivo

0,39

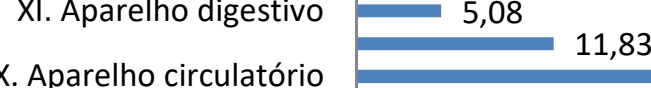

12,03

5,66

0,01

VII. Olho e anexos 0,00

V. Transtornos mentais e... $=0,99$

III. Sangue órgãos hemat e transt... 0,51

I. Algumas doenças infecciosas e...

4,35

16,60

Gráfico 1- Proporção dos grupos de causa de mortalidade - Brasil - 2015

Fonte: Elaboração própria a partir dos dados do MS - SIM (DATASUS).
} 


\subsection{Grupos de causas de mortalidade por residência no Espírito Santo, Minas Gerais, Rio De Janeiro e São Paulo em 2015}

As causas de mortalidade nos quatro Estados da região Sudeste seguem a tendência do Brasil, com maior incidência das doenças do aparelho circulatório, com índices acima dos $25 \%$; seguidas das neoplasias que, em todos, ultrapassaram os $16 \%$. Em Minas Gerais, Rio de Janeiro e São Paulo as doenças do aparelho respiratório aparecem em terceiro lugar, e as causas externas de mortalidade em quarto. No Espírito Santo, as causas externas ocupam a terceira colocação, com um índice que chega a 16,30\%, uma grande diferença proporcional em relação aos demais Estados. São Paulo, por exemplo, possui um índice de 8,15\%, ou seja, a metade do percentual apresentado pelo Espírito Santo. A menor incidência nos Estados diz respeito às doenças do olho e anexos (Tabela 1 ).

Outro ponto que merece destaque refere-se aos baixos percentuais de mortes causadas por algumas doenças infecciosas e parasitárias (menos de 6\% em todos os Estados). Antes da transição epidemiológica estas eram as causas da maior parte das mortes. Essa redução das doenças infecciosas e parasitárias tem ocorrido paulatinamente no Brasil. Como afirma Prata (1992), na década de 1930 elas eram responsáveis por 46\% do total de óbitos da população, enquanto em 1985 diminuiu para apenas 7\%. Os números demonstram que, apesar desse avanço, muito ainda precisa de ser feito, pois 25.386 pessoas morreram em 2015 no Sudeste em decorrência de doenças deste tipo.

Houve diminuição também no grupo de causas no XVI (algumas afecções originadas no período perinatal). Sendo assim, é possível dizer que a diminuição de óbitos por esses grupos de causas está diretamente relacionada ao avanço na medicina nesse período, com a realização de exames mais apurados que permitem a identificação mais precisa das doenças que acometem a população, além do maior acesso à assistência médica, de maneira geral e aos medicamentos necessários ao tratamento das doenças e a prática da medicina preventiva.

A geógrafa Damiani (1991, p. 32) aponta que entre os principais fatores da redução da mortalidade e do controle das doenças infecto-contagiosas no mundo são os "fatores sócioeconômicos, os fatores sanitários e os progressos da medicina", como melhorias nas condições de saneamento básico e do nível de vida em geral, descoberta de analgésicos e desenvolvimento de pesquisas. A causa no XVIII (sintomas, sinais e achados anormais de exames clínicos e de laboratório não classificados em outra parte) apresentou resultados 
discrepantes entre os Estados. Como afirma o DATASUS (2008, p. 1), as categorias deste grupo incluem "aqueles sintomas e afecções menos bem definidas que, sem que tenha havido o necessário estudo do caso para se estabelecer um diagnóstico final, podem conduzir com igual possibilidade a duas ou mais doenças diferentes ou a dois ou mais aparelhos do corpo". No Espírito Santo, o índice não chega a 1\%, enquanto que em Minas Gerais, ultrapassa os $8 \%$, demonstrando que este último Estado necessita de ampliar e aprofundar as investigações sobre as mortes dos pacientes.

\begin{tabular}{|c|c|c|c|c|c|c|c|c|}
\hline \multirow{2}{*}{ Capítulo CID-10 } & \multicolumn{4}{|c|}{ Número absoluto } & \multicolumn{4}{|c|}{ Proporção (\%) } \\
\hline & ES & MG & RJ & SP & ES & MG & RJ & SP \\
\hline $\begin{array}{l}\text { I. Algumas doenças infecciosas e } \\
\text { parasitárias }\end{array}$ & 681 & 5.978 & 7.645 & 11.082 & $3,05 \%$ & $4,55 \%$ & $5,76 \%$ & $3,85 \%$ \\
\hline II. Neoplasias (tumores) & 4.010 & 21.762 & 21.268 & 52.890 & $17,96 \%$ & $16,58 \%$ & $16,03 \%$ & $18,39 \%$ \\
\hline $\begin{array}{l}\text { III. Doenças sangue órgãos } \\
\text { hemat. e transt. imunitár. }\end{array}$ & 84 & 785 & 805 & 1.186 & $0,38 \%$ & $0,60 \%$ & $0,61 \%$ & $0,41 \%$ \\
\hline $\begin{array}{l}\text { IV. Doenças endócrinas } \\
\text { nutricionais e metabólicas }\end{array}$ & 1.383 & 7.135 & 7.636 & 13.628 & $6,19 \%$ & $5,44 \%$ & $5,75 \%$ & $4,74 \%$ \\
\hline $\begin{array}{l}\text { V. Transtornos mentais e } \\
\text { comportamentais }\end{array}$ & 258 & 2.097 & 785 & 2.435 & $1,16 \%$ & $1,60 \%$ & $0,59 \%$ & $0,85 \%$ \\
\hline VI. Doenças do sistema nervoso & 801 & 4.028 & 3.291 & 9.339 & $3,59 \%$ & $3,07 \%$ & $2,48 \%$ & $3,25 \%$ \\
\hline VII. Doenças do olho e anexos & - & 4 & 3 & 3 & - & $0,00 \%$ & $0,00 \%$ & $0,00 \%$ \\
\hline $\begin{array}{l}\text { VIII. Doenças do ouvido e da } \\
\text { apófise mastóide }\end{array}$ & 3 & 21 & 17 & 32 & $0,01 \%$ & $0,02 \%$ & $0,01 \%$ & $0,01 \%$ \\
\hline $\begin{array}{l}\text { IX. Doenças do aparelho } \\
\text { circulatório }\end{array}$ & 6.443 & 33.682 & 38.313 & 85.071 & $28,85 \%$ & $25,66 \%$ & $28,87 \%$ & $29,57 \%$ \\
\hline $\begin{array}{l}\text { X. Doenças do aparelho } \\
\text { respiratório }\end{array}$ & 2.174 & 16.231 & 16.866 & 39.330 & $9,73 \%$ & $12,36 \%$ & $12,71 \%$ & $13,67 \%$ \\
\hline $\begin{array}{l}\text { XI. Doenças do aparelho } \\
\text { digestivo }\end{array}$ & 1.113 & 6.664 & 5.871 & 16.216 & $4,98 \%$ & $5,08 \%$ & $4,42 \%$ & $5,64 \%$ \\
\hline $\begin{array}{l}\text { XII. Doenças da pele e do tecido } \\
\text { subcutâneo }\end{array}$ & 87 & 578 & 776 & 1.271 & $0,39 \%$ & $0,44 \%$ & $0,58 \%$ & $0,44 \%$ \\
\hline $\begin{array}{l}\text { XIII. Doenças lín. osteomuscular e } \\
\text { tec. conjuntivo }\end{array}$ & 83 & 723 & 557 & 1.316 & $0,37 \%$ & $0,55 \%$ & $0,42 \%$ & $0,46 \%$ \\
\hline $\begin{array}{l}\text { XIV. Doenças do aparelho } \\
\text { geniturinário }\end{array}$ & 681 & 3.979 & 5.390 & 10.039 & $3,05 \%$ & $3,03 \%$ & $4,06 \%$ & $3,49 \%$ \\
\hline XV. Gravidez parto e puerpério & 43 & 131 & 186 & 325 & $0,19 \%$ & $0,10 \%$ & $0,14 \%$ & $0,11 \%$ \\
\hline $\begin{array}{l}\text { XVI. Algumas afec. originadas no } \\
\text { período perinatal }\end{array}$ & 351 & 1.866 & 1.642 & 4.013 & $1,57 \%$ & $1,42 \%$ & $1,24 \%$ & $1,40 \%$ \\
\hline $\begin{array}{l}\text { XVII. Malf. cong. deformid. e } \\
\text { anomalias cromossômicas }\end{array}$ & 279 & 995 & 858 & 2.279 & $1,25 \%$ & $0,76 \%$ & $0,65 \%$ & $0,79 \%$ \\
\hline $\begin{array}{l}\text { XVIII. Sint.sinais e achados } \\
\text { anorm. ex.clín. e laborat. }\end{array}$ & 219 & 10.613 & 7.542 & 13.740 & $0,98 \%$ & $8,08 \%$ & $5,68 \%$ & $4,78 \%$ \\
\hline $\begin{array}{l}\text { XX. Causas externas de } \\
\text { morbidade e mortalidade }\end{array}$ & 3.639 & 14.002 & 13.263 & 23.450 & $16,30 \%$ & $10,67 \%$ & $9,99 \%$ & $8,15 \%$ \\
\hline Total & 22.332 & $\begin{array}{c}131.27 \\
4\end{array}$ & $\begin{array}{c}132.71 \\
4\end{array}$ & $\begin{array}{c}287.64 \\
5\end{array}$ & $100,00 \%$ & $\begin{array}{c}100,00 \\
\%\end{array}$ & $\begin{array}{c}100,00 \\
\%\end{array}$ & $\begin{array}{c}100,00 \\
\%\end{array}$ \\
\hline
\end{tabular}

Tabela 1- Óbitos por grupo de causas nos estados da região sudeste - 2015 Fonte: Elaboração própria a partir dos dados do MS - SIM (DATASUS). 
Do total de mortes em números absolutos, 312.711 foram masculinas e 260.953 femininas.

Os homens constituem o grupo que mais morre, nas diferentes causas $(54,48 \%)$, contra $45,46 \%$ de mulheres. Os demais constam como sexo ignorado.

Entre os óbitos da população residente na região Sudeste do sexo masculino, a maior parte faleceu por doenças do aparelho circulatório (84.701 homens ou 27,09\%), seguidas pelas neoplasias (52.931 homens ou 16,93\%) e pelas causas externas ( 42.572 homens ou $13,61 \%)$. Com relação às mulheres, a maioria também sofreu com doenças do aparelho circulatório (78.770 mulheres ou $30,19 \%)$, seguidas das neoplasias (46.980 mulheres ou $18 \%$ ) e das doenças do aparelho respiratório (36.541 mulheres ou 14\%), como pode-se observar no Gráfico 2.

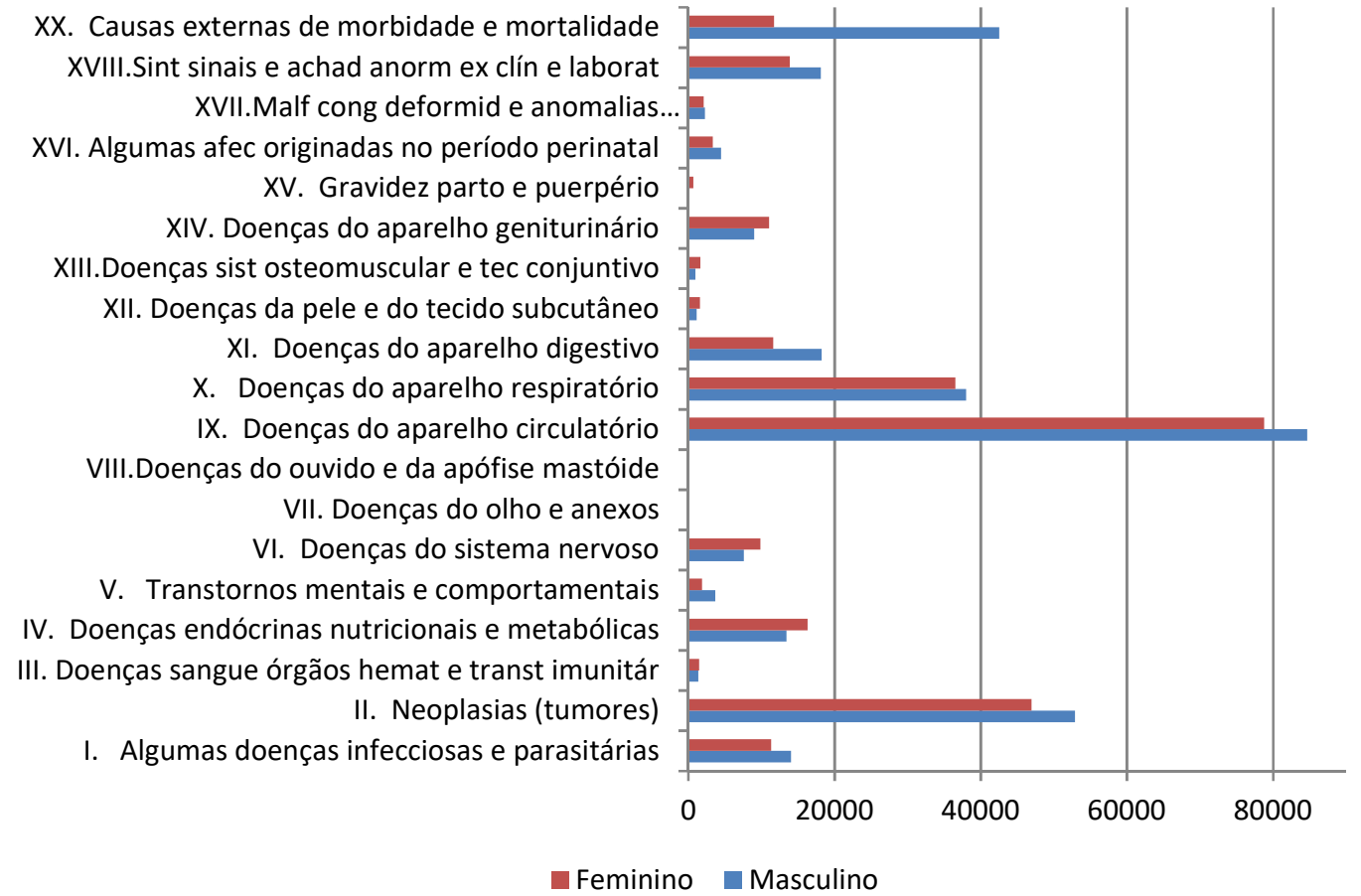

Gráfico 2 - Óbitos por grupo de causas e sexo -região sudeste - 2015

Fonte: Elaboração própria a partir dos dados do MS - SIM (DATASUS).

A análise do indicador razão de sexo demonstra que os homens do Sudeste morrem de causas externas em quantidade muito superior às mulheres (razão de sexo igual a 363,4 ). Ou seja, por cada 100 mulheres, morrem 363,4 homens. As doenças do olho e anexos são a segunda causa que mais diferencia a mortalidade entre homens e mulheres na região como um todo: por cada 100 mulheres, morrem 233,3 homens. Em seguida, aparecem as doenças do ouvido e da apófise mastoide e os transtornos mentais e comportamentais. Cabe 
ressaltar que o uso de drogas e a ingestão de bebidas alcoólicas são enquadrados como transtornos mentais. As doenças endócrinas nutricionais e metabólicas, as de pele e do tecido subcutâneo, as do sistema osteomuscular e tecido conjuntivo e as do aparelho geniturinário, por sua vez, atingem mais as mulheres. A razão de sexo das mortes na gravidez, parto e puerpério é igual a zero, pois só atingem as mulheres.

De modo geral, estes dados demonstram que as doenças que eram as maiores causadoras de morte antes da transição epidemiológica deram lugar àquelas "próprias da idade", o que reflete o envelhecimento populacional, pois as pessoas idosas tendem a adquirir doenças crônico-degenerativas que as levam à morte. Anteriormente, muitos morriam por doenças infecciosas em idades mais jovens, sendo este um dos fatos que ocasionava a baixa expectativa de vida brasileira, de 33,4 anos para os homens e 34,6 para as mulheres, em 1910 (IBGE, 2003). Em 2015, a expectativa de vida da população brasileira já havia passado para 75,5 anos (IBGE, 2016b).

Este fato pode ser percebido por meio da verificação da distribuição por faixa etária das mortes causadas por neoplasias no Sudeste em 1996 e 2015, que teve um aumento substancial entre as pessoas com mais de 50 anos, conforme consta no Gráfico 3. Utilizamos o ano de 1996, pois as declarações de óbito passaram a ser codificadas utilizando-se a 10a Revisão da Classificação Internacional de Doenças, conhecida como CID-10, sendo que, até então, era utilizada a 9a Revisão (CID-9).

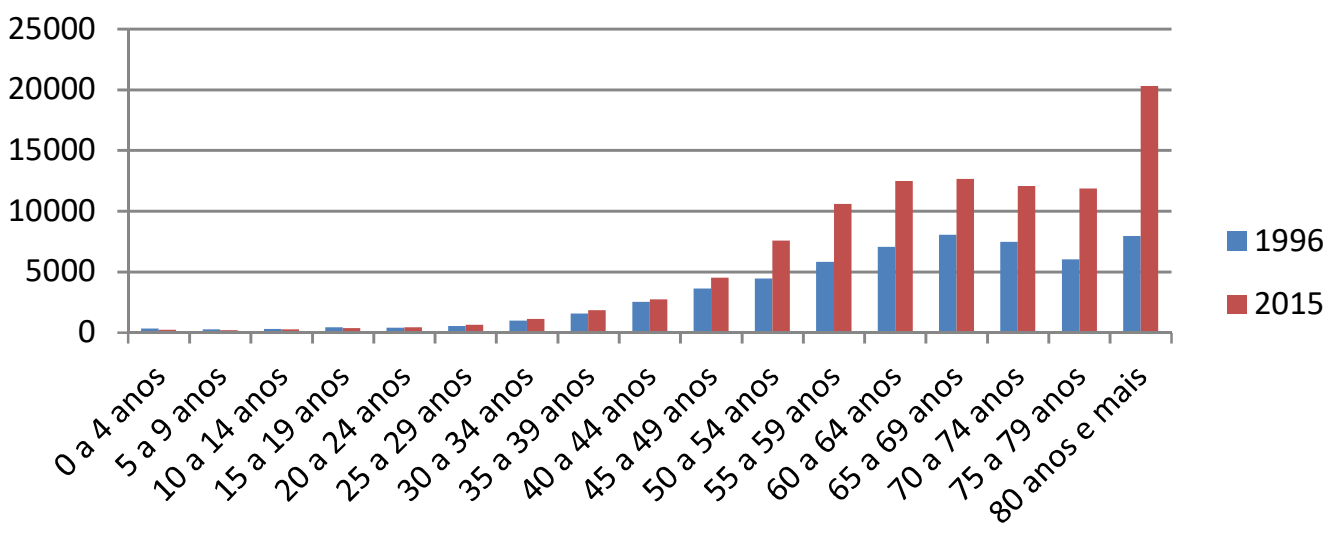

Gráfico 3 - Óbitos por neoplasias de acordo com a faixa etária - região Sudeste - 1996 e 2015 Fonte: Elaboração própria a partir dos dados do MS - SIM (DATASUS).

Além das doenças crônicas e degenerativas, merecem destaque as causas externas de morbilidade e mortalidade que, como já exposto, encontram-se entre as quatro causas que 
mais levam a óbito no Sudeste. As chamadas "mortes violentas" (CASTIGLIONI, 2012), que enquadram-se nessa modalidade, diferem dos demais tipos de causas externas por suas características específicas. Duarte e Barreto (2012) apontam que:

\footnotetext{
O crescimento da violência representa um dos maiores e mais difíceis desafios do novo perfil epidemiológico do Brasil. [...] O aumento da mortalidade por causas externas, observado a partir da década de 1980, deve-se principalmente aos homicídios (com 52 mil óbitos em 2010) e aos acidentes de transporte terrestre (com 42,5 mil óbitos em 2010), com destaque em grandes centros urbanos (DUARTE; BARRETO, 2012, p. 531).
}

A maioria das causas deste grupo decorre das particularidades e dos problemas socioeconômicos e culturais presentes, sobretudo nas grandes aglomerações urbanas, e, nesse contexto, percebe-se a importância do Ordenamento Territorial, entendido por Oliveira (2002) apud Papudo (2007) "como todo o acto de estabelecer políticas direccionadas para a garantia do equilíbrio das condições de vida nas diferentes partes de um determinado território, isto é, são todos os actos públicos orientados para a obtenção de uma qualidade de vida digna" (p.36).

Os estados do Sudeste apresentam conhecidos e elevados índices de mortes violentas. Adorno (2002, p. 89) afirma que "as taxas de criminalidade violenta no Brasil em cidades como Rio de Janeiro e São Paulo, são superiores inclusive às taxas de algumas metrópoles norte-americanas". Nesse sentido, vale discutir e aprofundar as análises dessas mortes no contexto dessa região, que é a mais urbanizada do país.

\subsection{Causas externas de mortalidade na região sudeste}

As mortes por causas externas são ocasionadas por causas intencionais ou não intencionais. Cabe ressaltar que, além das causas diretamente relacionadas com as mortes violentas como um todo, nesse grupo também se encontram as causas que se relacionam com o processo de envelhecimento da população como as quedas, por exemplo.

De acordo com a nota técnica sobre mortalidade do DATASUS, essas causas podem ser: acidentes de transporte, lesões auto provocadas voluntariamente (como o suicídio, por exemplo), agressões, eventos (fatos) cuja intenção é indeterminada, intervenções legais e operações de guerra e outras causas externas, complicações de assistência médica e cirúrgica, sequelas de causas externas de morbilidade e de mortalidade, fatores 
suplementares relacionados com as causas de morbilidade e de mortalidade classificados em outra parte.

Reitera-se que no Estado do Espírito Santo, no ano de 2015, as causas externas aparecem como a terceira maior causa de morte, perdendo apenas para as doenças do aparelho circulatório e neoplasias. Nos demais Estados da região Sudeste, estas aparecem como a quarta maior causa de morte, pois perdem a posição para as doenças do aparelho respiratório.

A distribuição por sexo do total de mortes por causas externas em todos os Estados do Sudeste em 2015, evidencia que os homens são os que mais morrem por causas externas. Em números absolutos isso representa uma diferença de mais de 30 mil falecimentos. Em Minas Gerais e no Espírito Santo, os óbitos masculinos representam $80 \%$ de todas as mortes. No Rio de Janeiro e em São Paulo chegam a 76\% e 78\%, respectivamente. Esse fato está diretamente relacionado com as diferenças comportamentais e de estilo de vida entre homens e mulheres. Homens, geralmente, são os que mais se expõe à situações de risco, são mais aventureiros e audaciosos, além do fato de buscarem menos os serviços de saúde do que as mulheres, como afirmam Gomes et al. (2007). Os índices de mortalidade, portanto, são influenciados por essas diferenças entre os sexos, principalmente por questões de socialização masculina.

Em relação às classificações, as mortes por agressões e acidentes de transporte são as predominantes entre as causas externas em todos os Estados (Gráfico 4). Vale ressaltar que em alguns deles predominou o grande grupo "Outras causas externas de lesões acidentais", todavia, esta categoria agrupa, como o próprio nome diz, várias causas que provocaram lesões. Sendo assim, para este estudo, foram selecionados os dois grupos específicos de causas externas de mortalidade no estado do Espírito Santo, Minas Gerais, Rio de Janeiro e São Paulo no ano de 2015 segundo as variáveis sexo e faixa etária. 


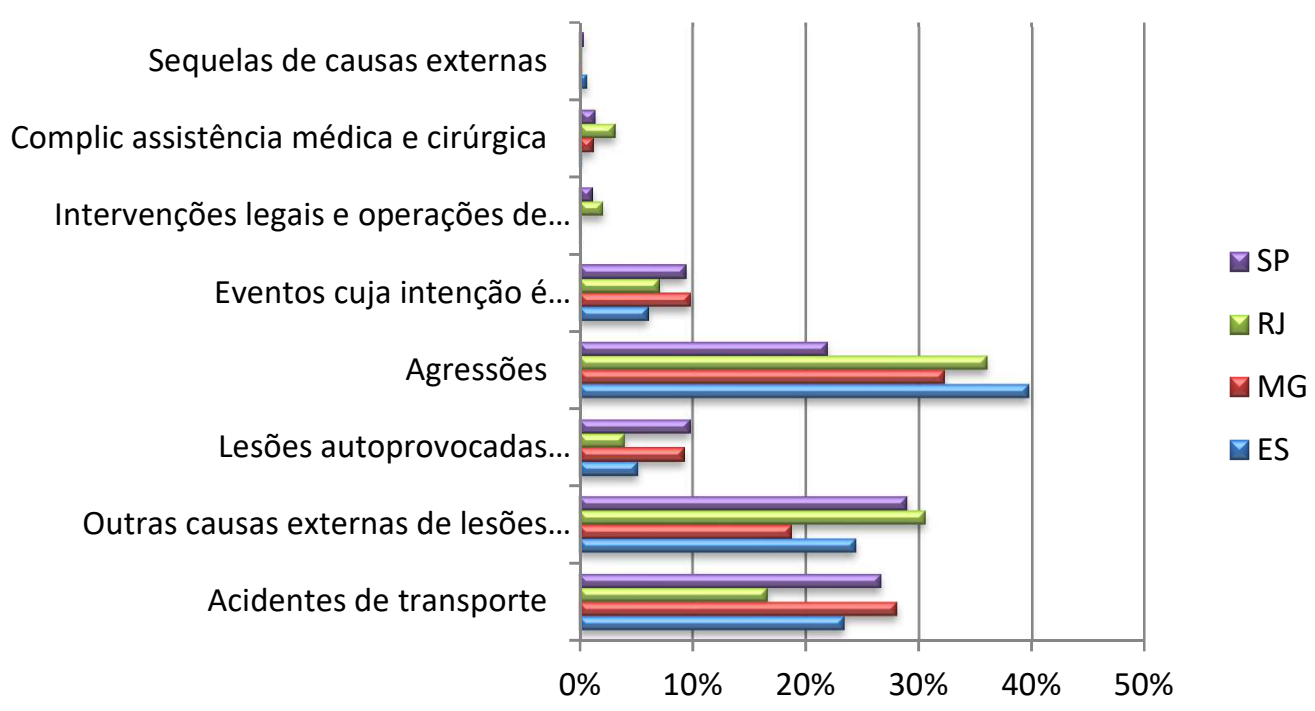

Gráfico 4 - Óbitos por tipo de causas externas entre os Estados da região sudeste - 2015 Fonte: Elaboração própria a partir dos dados do MS - SIM (DATASUS).

Nesse sentido, são aprofundadas nos itens seguintes as análises sobre as duas principais causas externas de morbidade e mortalidade: acidentes de transporte e agressões.

\subsubsection{Acidentes de transporte}

Acidente de transporte é todo aquele que envolve um veículo destinado, ou usado no momento do acidente, principalmente para o transporte de pessoas ou de mercadorias de um lugar para o outro. Este grupo contém os seguintes agrupamentos: Pedestre traumatizado num acidente de transporte; Ciclista traumatizado num acidente de transporte; Motociclista traumatizado num acidente de transporte; Ocupante de triciclo motorizado traumatizado num acidente de transporte; Ocupante de um automóvel traumatizado num acidente de transporte; Ocupante de uma caminhonete traumatizado num acidente de transporte; Ocupante de um veículo de transporte pesado traumatizado num acidente de transporte; Ocupante de um ônibus traumatizado num acidente de transporte; Outros acidentes de transporte terrestre; Acidentes de transporte por água; Acidentes de transporte aéreo e espacial; Outros acidentes de transporte e os não especificados.

Destes, os que mais morreram na região Sudeste foram os ocupantes de automóveis traumatizados num acidente de transporte, com $25,17 \%$, seguidos dos motociclistas, com $24,18 \%$ e dos pedestres, com $23,04 \%$ (Tabela 2). Esse fato pode ser observado diariamente 
na mídia e no dia a dia das cidades, onde motoristas de automóveis, motociclistas e pedestres frequentemente estão envolvidos em acidentes fatais.

\begin{tabular}{|c|c|c|c|c|c|c|}
\hline Grupo CID-10 & ES & MG & RJ & SP & $\begin{array}{c}\text { No } \\
\text { absolut } \\
\text { o }\end{array}$ & $\begin{array}{c}\text { Percentu } \\
\text { al }\end{array}$ \\
\hline & & & & 1.31 & & \\
\hline Ocupante automóvel & 222 & 1.438 & 368 & $\begin{array}{c}3 \\
1.47\end{array}$ & 3.341 & $25,17 \%$ \\
\hline Motociclista & 290 & 883 & 559 & $\begin{array}{c}8 \\
1.58\end{array}$ & 3.210 & $24,18 \%$ \\
\hline Pedestre & 135 & 606 & 728 & $\begin{array}{c}9 \\
1.31\end{array}$ & 3.058 & $23,04 \%$ \\
\hline Outros acidentes de transporte terrestre & 150 & 604 & 390 & 1 & 2.455 & $18,49 \%$ \\
\hline Ciclista & 24 & 127 & 81 & 241 & 473 & $3,56 \%$ \\
\hline $\begin{array}{l}\text { Ocupante veículo de transporte pesado } \\
\text { Outros acidentes de transporte e os não } \\
\text { especificados }\end{array}$ & 22 & $\begin{array}{l}88 \\
112\end{array}$ & 29 & $\begin{array}{l}139 \\
112\end{array}$ & $\begin{array}{l}278 \\
232\end{array}$ & $2,09 \%$ \\
\hline Ocupante ônibus & 3 & 25 & 32 & 27 & 87 & $0,66 \%$ \\
\hline Ocupante caminhonete & - & 37 & 6 & 29 & 72 & $0,54 \%$ \\
\hline Acidentes de transporte aéreo e espacial & 2 & 12 & 2 & 15 & 31 & $0,23 \%$ \\
\hline Acidentes de transporte por água & 3 & 2 & 9 & 9 & 23 & $0,17 \%$ \\
\hline Ocupante triciclo motorizado & - & 8 & - & 7 & 15 & $0,11 \%$ \\
\hline & \multicolumn{4}{|r|}{6.27} & & \\
\hline Total & 853 & 3.942 & 2.210 & 0 & 13.275 & $100 \%$ \\
\hline
\end{tabular}

Tabela 2- Pessoas traumatizados em acidentes de transporte por tipo de transporte - região sudeste - Brasil 2015.

Fonte: Elaboração própria a partir dos dados do MS - SIM (DATASUS).

Bastos (2011, p. 9), por meio de sua pesquisa nos estados brasileiros considerou que a "situação da mortalidade no trânsito é um grave problema nacional, sobretudo nos estados mais pobres, onde os índices de mortes por veículo-quilômetro atingem números extremamente elevados". A maior parte das mortes por acidentes de transportes (6.270 em números absolutos), ocorreu no Estado de São Paulo, com 47,23\%, o que pode ser explicado pela maior frota de veículos, vias e maior volume de pedestres que lá circulam. Em 2015 a população do Estado de São Paulo foi estimada pelo IBGE em 44.396 .484 habitantes, representando $21,7 \%$ da população brasileira e $51,8 \%$ da população residente na região sudeste (IBGE, 2015). O estado de Minas Gerais ficou na segunda colocação em acidentes de transportes (29,69\%), seguido do Rio de Janeiro (16,65\%) e Espírito Santo (6,43\%).

Os resultados obtidos indicam que os óbitos por acidentes de transportes são muito maiores entre jovens, principalmente do sexo masculino (Gráfico 5). A faixa etária em que mais pessoas morreram (tanto homens quanto mulheres) foi a de 20 a 24 anos, idade em 
que os jovens estão iniciando a vida adulta e passam a usar com maior frequência e, muitas vezes, menos responsabilidade os meios de transporte. Essa também é a faixa etária em que muitos jovens já atingiram a idade mínima necessária para solicitar a emissão da Carteira Nacional de Habilitação (18 anos) e com isso obter a permissão para dirigir.

Ao observar o Gráfico 5, percebe-se que, em geral, o número de óbitos de homens, vai diminuindo com o avançar da idade, fato que comprova a relação entre juventude e mortes por acidentes de transporte. Já entre as mulheres, há uma relativa proximidade no número de óbitos a partir de 15 anos. As proporções são parecidas até à faixa etária de 80 anos e mais, indicando uma certa regularidade na tendência de óbitos por acidentes de transporte entre as mulheres residentes na região Sudeste do Brasil em 2015.

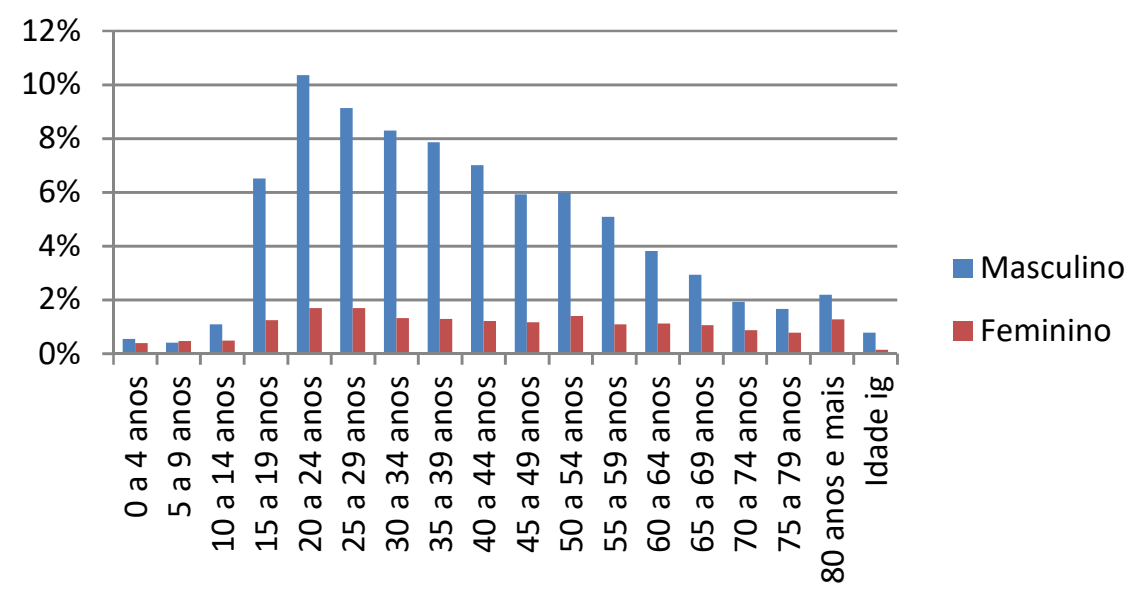

Gráfico 5 - Óbitos por acidentes de transporte, segundo faixa etária e sexo - região sudeste - 2015 Fonte: Elaboração própria a partir dos dados do MS - SIM (DATASUS).

A diferença entre os sexos é muito acentuada. As pessoas do sexo masculino correspondem a $81,39 \%$ das mortes por acidentes de transporte, enquanto as mulheres representam somente $18,61 \%$. Esse fato está relacionado diretamente à fatores comportamentais.

Essa diferenciação por sexo fica ainda mais perceptível quando observamos a razão de sexo (Gráfico 6). Em todas as faixas etárias, a razão de sexo é maior que 100 , exceto na faixa etária de 5 a 9 anos, o que indica que há predomínio de homens no quesito analisado, nesse caso, a mortalidade por acidentes de transporte. A faixa etária com maior destaque é a de 30 a 34 anos, com razão de sexo 628. Ou seja, são 628 óbitos masculinos para cada 100 óbitos femininos. 


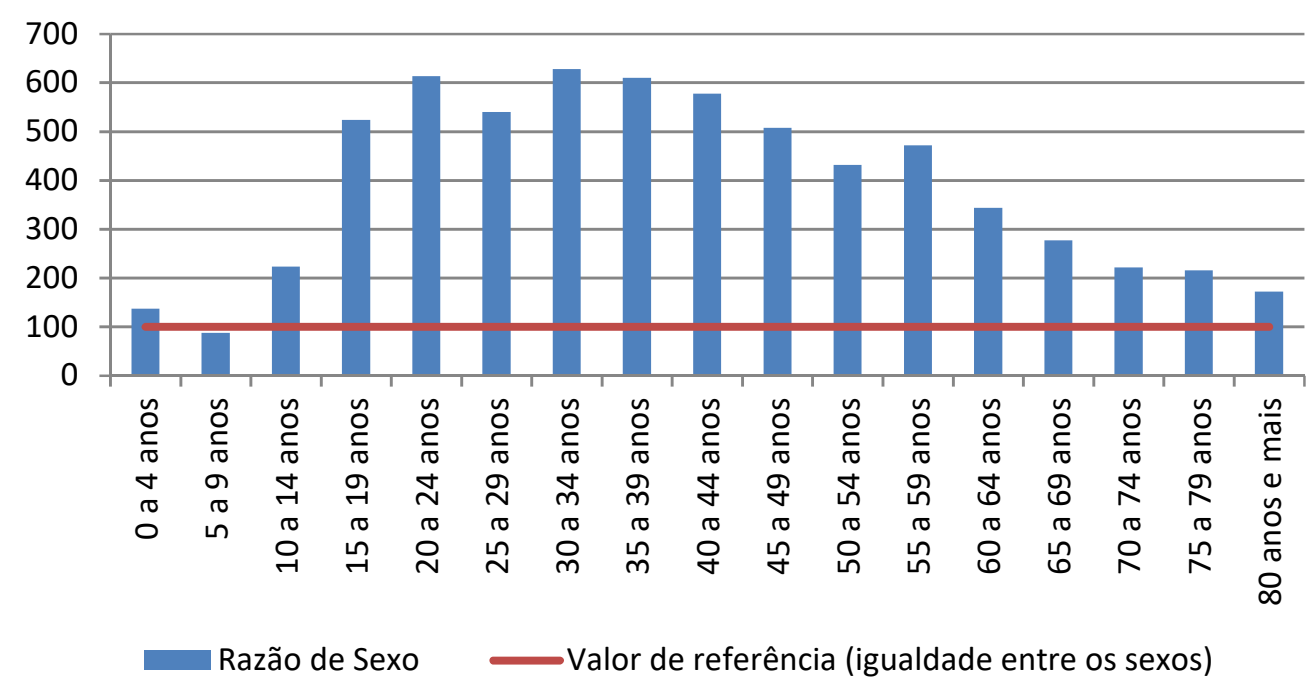

Gráfico 6 - Razão de sexos - óbitos por acidentes de transporte - região sudeste - 2015 Fonte: Elaboração própria a partir dos dados do MS - SIM (DATASUS).

\subsubsection{Agressões}

São catalogados como agressão os homicídios e as lesões infligidas por outra pessoa, empregando qualquer meio, com a intenção de lesar (ferir) ou de matar. De acordo com o DATASUS ${ }^{1}$, as violências que são classificadas como agressão são de vários tipos (listados na Tabela 3). Na região Sudeste a causa que mais levou pessoas a óbito foram as agressões por meio de disparo de outra arma de fogo ou de arma não especificada, que representou $58,80 \%$. Junto com as outras mortes ocasionadas por outros tipos de arma de fogo, o índice chega a $66,55 \%$. Em segundo lugar aparecem as agressões por meio de objeto cortante ou penetrante, como facas e tesouras, com 12,07\% (Tabela 3).

\footnotetext{
${ }^{1}$ http://www.datasus.gov.br/cid10/V2008/WebHelp/x85_y09.htm
} 


\begin{tabular}{|c|c|c|c|c|c|c|}
\hline Categoria CID-10 & ES & MG & RJ & SP & № absolutos & $\begin{array}{l}\text { Percentu } \\
\text { al }\end{array}$ \\
\hline $\begin{array}{l}\text { Agressão meio drog. medic.e subst. } \\
\text { biológicas }\end{array}$ & 0 & 0 & 0 & 2 & 2 & $0,01 \%$ \\
\hline Agressão $p /$ meio de subst. corrosivas & 0 & 0 & 0 & 1 & 1 & $0,01 \%$ \\
\hline Agressão p/pesticidas & 0 & 1 & 0 & 0 & 1 & $0,01 \%$ \\
\hline $\begin{array}{l}\text { Agressão outr. prod. quim. subst. nocivas } \\
\text { espec. }\end{array}$ & 0 & 4 & 0 & 0 & 4 & $0,03 \%$ \\
\hline $\begin{array}{l}\text { Agressão prod. químicos e subst. nocivas } \\
\text { não especif. }\end{array}$ & 0 & 1 & 0 & 0 & 1 & $0,01 \%$ \\
\hline $\begin{array}{l}\text { Agressão enforc. estrangulamento } \\
\text { sufocação }\end{array}$ & 26 & 65 & 82 & 161 & 334 & $2,10 \%$ \\
\hline $\begin{array}{l}\text { Agressão p/meio de afogamento e } \\
\text { submersão }\end{array}$ & 2 & 5 & 2 & 6 & 15 & $0,09 \%$ \\
\hline Agressão disparo de arma de fogo de mão & 172 & 315 & 221 & 475 & 1.183 & $7,44 \%$ \\
\hline $\begin{array}{l}\text { Agressão disparo arma fogo de maior } \\
\text { calibre }\end{array}$ & 1 & 17 & 24 & 7 & 49 & $0,31 \%$ \\
\hline $\begin{array}{l}\text { Agressão disparo outr. arma de fogo ou } \\
\text { Não especificada }\end{array}$ & 920 & 2.882 & 2.937 & $\begin{array}{c}2.61 \\
5\end{array}$ & 9.354 & $58,80 \%$ \\
\hline Agressão p/meio de material explosivo & 1 & 0 & 0 & 1 & 2 & $0,01 \%$ \\
\hline Agressão - fumaça fogo e chamas & 4 & 20 & 50 & 33 & 107 & $0,67 \%$ \\
\hline $\begin{array}{l}\text { Agressão vapor água gases ou objetos } \\
\text { quentes }\end{array}$ & 0 & 4 & 3 & 1 & 8 & $0,05 \%$ \\
\hline Agressão objeto cortante ou penetrante & 157 & 664 & 247 & 852 & 1.920 & $12,07 \%$ \\
\hline $\begin{array}{l}\text { Agressão } p / \text { meio de um objeto } \\
\text { contundente }\end{array}$ & 112 & 297 & 62 & 547 & 1.018 & $6,40 \%$ \\
\hline $\begin{array}{l}\text { Agressão } p / \text { meio projeção de um lugar } \\
\text { elevado }\end{array}$ & 0 & 2 & 0 & 3 & 5 & $0,03 \%$ \\
\hline $\begin{array}{l}\text { Agressão proj. coloc. vitima obj. } \\
\text { movimento }\end{array}$ & 0 & 2 & 2 & 3 & 7 & $0,04 \%$ \\
\hline Agressão p/meio de impacto veic. a. motor & 0 & 3 & 4 & 28 & 35 & $0,22 \%$ \\
\hline Agressão $\mathrm{p} /$ meio de força corporal & 15 & 93 & 30 & 96 & 234 & $1,47 \%$ \\
\hline Agressão sexual p/meio de força física & 2 & 1 & 5 & 6 & 14 & $0,09 \%$ \\
\hline Negligencia e abandono & 0 & 3 & 1 & 1 & 5 & $0,03 \%$ \\
\hline Outr. sindr. de maus tratos & 18 & 5 & 1 & 11 & 35 & $0,22 \%$ \\
\hline Agressão p/outr.meios espec. & 0 & 16 & 17 & 15 & 48 & $0,30 \%$ \\
\hline Agressão p/meios não especif. & 18 & 125 & 1.098 & 286 & 1.527 & $9,60 \%$ \\
\hline Total & 1.448 & 4.525 & 4.786 & $\begin{array}{c}5.15 \\
0\end{array}$ & 15.909 & $100,00 \%$ \\
\hline
\end{tabular}

Tabela 3 - Óbitos por tipos de agressões - região sudeste - 2015

Fonte: Elaboração própria a partir dos dados do MS - SIM (DATASUS).

O Estado que apresentou o maior número de mortes por agressões foi São Paulo, com 32,37\%, seguido do Rio de Janeiro, com 30,08\%. Minas Gerais aparece na terceira colocação, com $28,44 \%$, ou seja, índices próximos aos dois primeiros e destoantes do Espírito Santo, que apresentou o menor índice, 9,10\%. 
Esses dados demonstram como a população da região Sudeste tem sido acometida pelas mortes por armas de fogo, que refletem a violência vivenciada no dia a dia, fruto, entre outros, do tráfico de drogas, constantemente divulgado pela imprensa nacional e internacional. Sabe-se, portanto, que a maior parte das agressões ocorre com a utilização de armas de fogo e estas têm vitimado, principalmente, os homens em idades jovens. 0 número de pessoas mortas por agressão foi muito maior entre as pessoas do sexo masculino na faixa etária de 20 a 24 anos, seguindo a tendência das mortes por acidentes de transportes. A maior proporção de mortes encontra-se entre as pessoas que possuem de 15 a 34 anos (Gráfico 7).

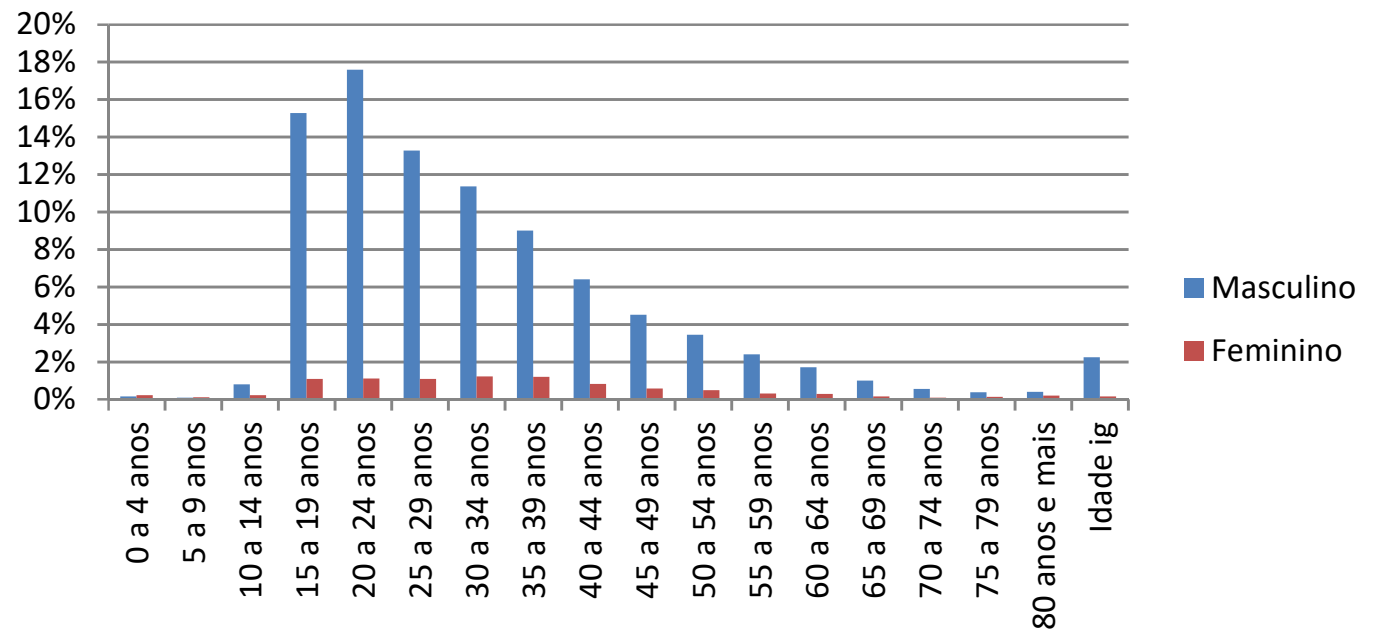

Gráfico 7- Óbitos por agressões, segundo faixa etária e sexo - região sudeste - 2015 Fonte: Elaboração própria a partir dos dados do MS - SIM (DATASUS).

A razão de sexo por agressões confirma que há predomínio de homens, porém, não é unânime. Nas faixas etárias 0 a 4 anos e de 5 a 9 anos o indicador ficou abaixo de 100, ou seja, houve mais mortes de meninas do que de meninos. Nas demais idades os homens predominaram, com destaque, novamente, para a faixa etária de 20 a 24 anos, que apresentou maior diferenciação entre os sexos: morreram 1575 homens para cada 100 mulheres. Uma diferença exorbitante que ressalta a predominância da mortalidade masculina (Gráfico 8). 


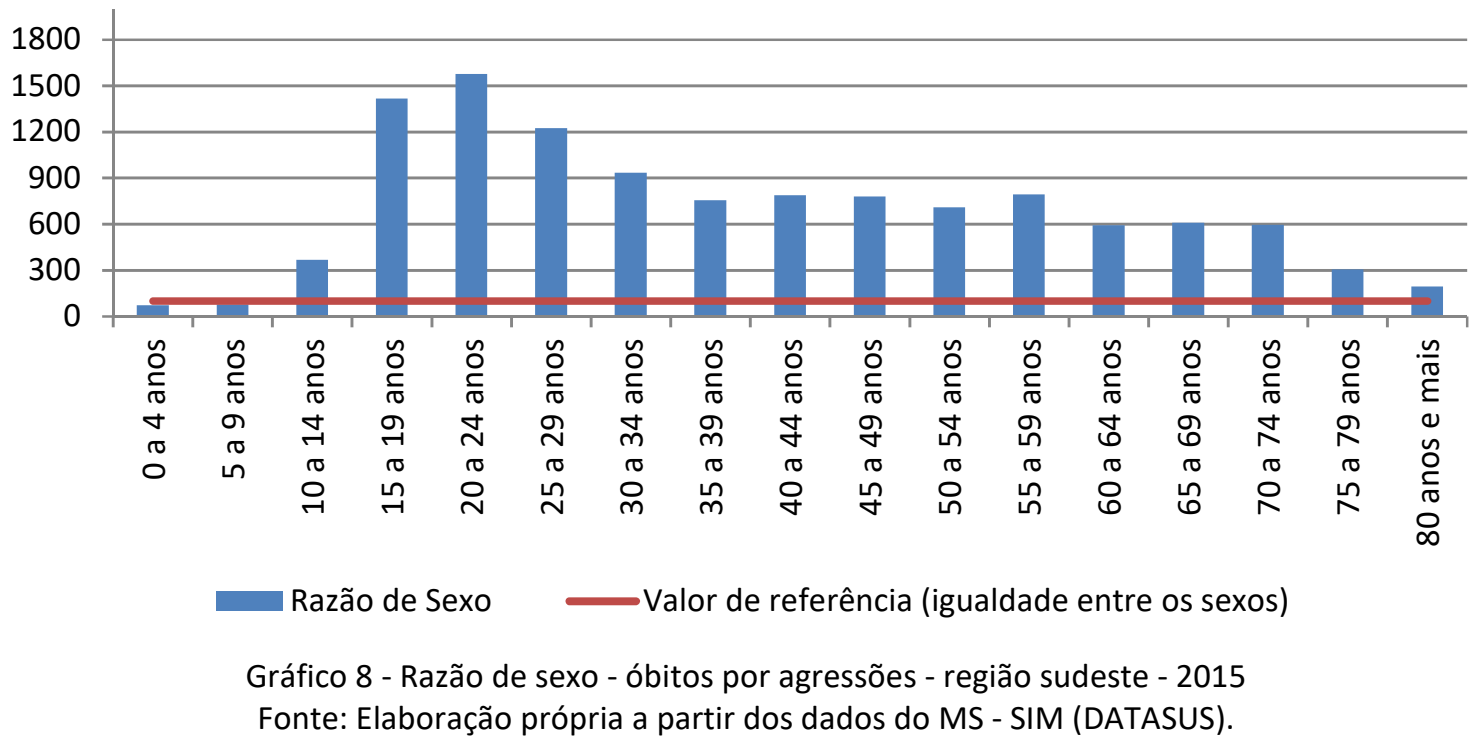

\section{Considerações finais}

Este estudo nos dá um panorama da transição epidemiológica pela qual passa a região Sudeste e o Brasil. De acordo com os resultados apresentados, as mortes causadas por doenças crônico-degenerativas representaram uma maior proporção em 2015, enquanto as causadas por doenças infecciosas e parasitárias diminuíram de $50 \%$ para menos de $6 \%$ na região Sudeste. As causas externas são, nesse contexto, uma das principais causas de óbito.

Observa-se que as mudanças no estilo de vida e comportamento da população têm sido fatores importantes na distribuição proporcional dos grupos de causas de mortalidade. 0 processo de transição epidemiológica no Brasil ocorre de forma um pouco diferenciada do modelo tradicional indicando uma contra-transição; "o processo não se resolve de maneira clara, criando uma situação que a morbi-mortalidade persiste elevada para ambos os padrões, caracterizando uma transição prolongada" (SCHRAMM, et al., 2004 p. 898). O que se observa é um processo de sobreposição das causas de mortes. Mesmo que as doenças infecciosas e parasitárias não sejam mais a principal causa de mortalidade no país, acabam ressurgindo e ganhando um lugar na proporção de mortes.

Ao analisar as mortes por acidentes de transporte e agressões, percebe-se que os homens jovens são os mais afetados, o que demonstra a necessidade de se realizarem políticas 
públicas direcionadas para esse segmento. O grande volume de mortes por agressões refletem a violência cotidiana que a população brasileira enfrenta. Destaca-se ainda que a maior parte das agressões ocorre com a utilização de armas de fogo, numa relação direta com as disputas ocasionada pelo tráfico de drogas, principalmente no Rio de Janeiro.

Destarte, para melhoria desse quadro é necessário que se atente para maiores investimentos em prevenção, tanto no que refere às doenças degenerativas do organismo quanto às infecciosas e parasitárias, assim como no combate ao tráfico de drogas. É necessário atentar-se para a melhoria da qualidade de vida da população por meio da intervenção no meio ambiente em que se vive, ou seja, por meio do que se chama de Ordenamento Territorial. Investimentos em lazer, incentivos a hábitos alimentares mais saudáveis, bem como a prática regular de exercícios físicos são importantes caminhos a percorrer para a amenização do número de óbitos por doenças cardiovasculares e neoplasias. Já para tentar diminuir os óbitos por agressões, investimentos em educação, lazer, esporte e cultura são essenciais. No âmbito dos acidentes de trânsito, melhorias nas condições das estradas, na sinalização e na educação são essenciais.

Este estudo se limita pelos recortes temporal e espacial adotados, o que restringe os resultados. Faz-se necessário, para futuras investigações, realizar uma análise histórica da evolução dos grupos de causas de mortalidade ao longo de um período de tempo e em todas as regiões do Brasil. Dessa maneira será possível obter um panorama completo das mudanças no perfil epidemiológico do País.

\section{Referências bibliográficas}

ADORNO, Sérgio. Exclusão socioeconômica e violência urbana. Sociologias [online]. 2002, n.8, pp.84-135. ISSN 1517-4522. Disponível em: <http://dx.doi.org/10.1590/S1517-45222002000200005>. Acesso em: 27 jul. 2017.

BASTOS, Jorge Tiago. Geografia da mortalidade no trânsito no Brasil. 2011. Dissertação (Mestrado em Planejamento e Operação de Sistemas de Transportes) - Escola de Engenharia de São Carlos, Universidade de São Paulo, São Carlos, 2011. doi:10.11606/D.18.2011.tde-14032011-112111. Acesso em: 29 jul. 2018.

BEAUJEU-GARNIER, J. Geografia da população. São Paulo: Companhia Editora Nacional, 1980.

BRASIL. Ministério da Saúde. DATASUS. Informações de Saúde (TABNET). Estatísticas Vitais. Mortalidade - 1996 a 2015, pela CID-10. $2017 . \quad$ Disponível em: http://www2.datasus.gov.br/DATASUS/index.php?area=0205\&id=6937>. Acesso em: 31 jun. 2017. 
BRASIL. Ministério da Saúde. DATASUS. s.d. Mortalidade geral - 1996 a 2012. Notas técnicas. Disponível em: <http://tabnet.datasus.gov.br/cgi/sim/Mortalidade_Geral_1996_2012.pdf>. Acesso em: 06 de maio de 2017.

BRASIL. Ministério da Saúde. DATASUS. CID 10. Capítulo XVIII 2008. Disponível em: <http://www.datasus.gov.br/cid10/V2008/WebHelp/r00_r99.htm>. Acesso em: 06 jan. 2018.

CASTIGLIONI, Aurélia H.. Inter-relações entre os processos de transição demográfica, envelhecimento populacional e transição epidemiológica no Brasil. In: V CONGRESO DE ALAP Lastransicionesen América Latina y el Caribe. Cambios demográficos y desafíossociales presentes y futuros, 2012, Montevideo. 2012. Disponível em: <http://www.alapop.org/Congreso2012/DOCSFINAIS_PDF/ALAP_2012_FINAL537.pdf>. Acesso em: 28 jul. 2017.

DAMIANI, Amélia. População e geografia. São Paulo: Contexto, 1991.

DERRUAU, Max. Geografia Humana I. São Paulo: Martins Fontes, 1973.

DUARTE, E. C.; BARRETO, S. M. Transição demográfica e epidemiológica: a Epidemiologia e Serviços de Saúde revisita e atualiza o tema. Epidemiol. Serv. Saúde, Brasília , v. 21, n. 4, p. 529-532, dez. 2012 . Disponível em < http://scielo.iec.gov.br/scielo.php?script=sci_arttext\&pid=S1679-49742012000400001>. acessos em 29 jul. 2018.

GOMES R, NASCIMENTO EF, ARAÚJO FC. Por que os homens buscam menos os serviços de saúde do que as mulheres? As explicações de homens com baixa escolaridade e homens com ensino superior. Cad. Saúde Pública. 2007; 23(3). pp. 565-574.

INCA. Instituto Nacional do Câncer. Estimativas de Incidência e Mortalidade por Câncer em 2003. Disponível em: <http://www.inca.gov.br/releases/press_release_view_arq.asp?ID=34>. Acesso em: 09 de maio de 2017.

INSTITUTO BRASILEIRO DE GEOGRAFIA E ESTATÍSTICA - IBGE. Estatísticas do Século XX. Comunicação Social, 2003. Disponível em: http://www.ibge.gov.br/home/presidencia/noticias/29092003estatisticasecxxhtml.shtm. Acesso em: 26 jul. 2017.

INSTITUTO BRASILEIRO DE GEOGRAFIA E ESTATÍ́sTICA - IBGE. Tabela 200 - População residente, por sexo, situação e grupos de idade - Amostra - Características Gerais da População. Censo demográfico, 2010. Disponível em: https://sidra.ibge.gov.br/tabela/200\#resultado. Acesso em: 20 de maio de 2018.

INSTITUTO BRASILEIRO DE GEOGRAFIA E ESTATÍSTICA - IBGE. Síntese de Indicadores Sociais: uma análise das condições de vida da população brasileira: 2016. Rio de Janeiro: IBGE, 2016a. 141 p. Disponível em: < http://biblioteca.ibge.gov.br/visualizacao/livros/liv98965.pdf>. Acesso em: 25 abr. 2017.

INSTITUTO BRASILEIRO DE GEOGRAFIA E ESTATÍSTICA - IBGE. Tábua completa de mortalidade para o Brasil Breve análise da evolução da mortalidade no Brasil. Rio de Janeiro, 2016b. Disponível em: <ftp.ibge.gov.br/Tabuas_Completas_de_Mortalidade/Tabuas_Completas_de_Mortalidade_2015/tabua_de_m ortalidade_analise.pdf>. Acesso em: 26 jul. 2017.

INSTITUTO BRASILEIRO DE GEOGRAFIA E ESTATÍSTICA - IBGE. Estimativas da população residente no Brasil e Unidades da Federação com data de referência em 1o de julho de 2015. Estimativas de População. 2015. Disponível em:

<ftp://ftp.ibge.gov.br/Estimativas_de_Populacao/Estimativas_2015/estimativa_TCU_2015_20170614.pdf>. Acesso em: 27 jul. 2017.

JANNUZZI, P. M. Indicadores Sociais no Brasil: conceitos, fontes de dados e aplicações. 2 ed. Campinas, SP: Editora Alínea, 2003.

OMRAN A. The epidemiologic transition: a theory of the epidemiology of population change. Milbank Quarterly. 2005; vol. 83, no 4, pp. 731-757. Reprinted from The Milbank Memorial Fund Quarterly, Vol. 49, No. 4, Pt. 1, 1971. pp. 509-38. Disponível em: <https://www.ncbi.nlm.nih.gov/pmc/articles/PMC2690264/>. Acesso em: 28 jul. 2017.

PAPUDO, Rui Miguel, 2007. Indicadores de Ordenamento do Território: uma proposta metodológica. Dissertação de mestrado, Universidade de Lisboa, Lisboa. Disponível em: <http://hdl.handle.net/10451/454>. Acesso em: 05 nov. 2018. 
PEREIRA, R. A., ALVES-SOUZA, R. A., VALE, J. S. O processo de transição epidemiológica no Brasil: uma revisão. Revista Científica da Faculdade de Educação e Meio Ambiente, 2015; v. 6, n.1, pp. 99-108. Disponível em: http://www.faema.edu.br/revistas/index.php/Revista-FAEMA/article/view/322>. Acesso em: 29 jul. 2018.

PRATA, Pedro R.. A transição epidemiológica no Brasil. Cadernos de Saúde Pública vol. 8, no 2, Rio de Janeiro, 1992. Disponível em: <http://www.scielo.br/pdf/csp/v8n2/v8n2a08.pdf/>. Acesso em 02/05/2017.

RAMOS LR, Rosa TEC; OLIVEIRA ZM; MEDINA MCG; Santos FRG. Perfil do idoso em área metropolitana na região Sudeste do Brasil: resultados de inquérito domiciliar. Revista de Saúde Pública1993. 27(2), pp. 87-94. Disponível em: <http://www.scielo.br/pdf/rsp/v27n2/03>. Acesso em: 18 maio 2017.

SCHRAMM, J. M. A.; OLIVEIRA, A.F.; LEITE, I.C.; VALENTE, J.G.; GADELHA, A.M.J.; PORTELA, M.C.; CAMPOS, M. R. Transição epidemiológica e o estudo de carga de doença no Brasil. Ciência \& Saúde Coletiva, 9(4):897-908, 2004. Disponível em: <http://dx.doi.org/10.1590/S1413-81232004000400011>. Acesso em: 26 jul. 2017.

VERMELHO, L. L. ; MONTEIRO, M. F. G.. Transição Demográfica e Epidemiológica. In: MEDRONHO, R. A. Et al. Epidemiologia, SP : Editora Atheneu, 2002.

YUNES, João. Demografia e saúde pública. In.: SANTOS, J. L. F; LEVY, M. S. F.; SZMRECSÁNYI, T. (org.). Dinâmica da população: teoria, métodos e técnicas de análise. São Paulo: T.A. Queiroz, 1991. 